\title{
Non-operative management of a patella fracture: environmental considerations in the Subantarctic
}

\section{Fraser John Gould}

Medical Officer, British Antarctic Survey Medical Unit, United Kingdom

\begin{abstract}
Injuries occurring in the remote environment present particular challenges to healthcare professionals, and decisions need to be carefully made on an individual basis. This report describes the successful management of a patella fracture sustained on the Subantarctic island of South Georgia. A 36-year-old boating officer presented to the island surgery after sustaining an isolated closed injury to his left knee. On physical examination there was a large effusion palpable within the joint, and on subsequent radiography an undisplaced transverse fracture of the patella was apparent. The patient had an intact and competent extensor mechanism, and fulfilled indications for non-operative management. His clinical case was discussed with supervising consultants at the British Antarctic Survey Medical Unit in the United Kingdom, and radiographs forwarded electronically for an orthopaedic review. The decision was made to undertake medical evacuation of the patient. There were additional environmental factors to be considered in this situation. The terrain on South Georgia is rugged and unforgiving, there is a risk of injury posed by the local fauna (Arctocephalus gazella) during summer months, and emergency evacuation from the base would be difficult for any person with restricted mobility. A planned retrieval enabled our patient to continue rehabilitation and physiotherapy in the preferrential setting of his home country, without causing undue delay in time taken returning to work in this remote location.
\end{abstract}

(Int Marit Health 2017; 68, 3: 159-162)

Key words: knee, South Georgia, remote, evacuation

\section{INTRODUCTION}

Injuries occurring in the remote environment present particular challenges to healthcare professionals, and decisions need to be carefully made on a individual basis. This report describes the successful management of a patella fracture sustained on the island of South Georgia, an isolated mountainous archipelago surrounded by the cold seas of the South Atlantic (Fig. 1).

South Georgia is a British Overseas Territory independently governed by the Government of South Georgia and the South Sandwich Islands (GSGSSI), although it does not have a permanent population. There is no airstrip, and its location is over 600 nautical miles from the nearest dedicated hospital on the Falkland Islands. All transport to and from the country is via the sea, a voyage usually taking between three to five days. The
British Antarctic Survey (BAS) maintain a permanent presence at King Edward Point (KEP) Research Station, employing seven staff to provide boating and fisheries science support to GSGSSI officers. In the austral summer there may be 35 personnel working on the island, but in the winter this number drops down to only 9.

Due to the remote location, hazardous environment and potential need for search-and-rescue, a doctor is recruited annually to provide continuous medical support and training to all those present at KEP. These medical officers undertake a six-month preparatory period before deployment, including 'crash courses' in basic dentistry, physiotherapy and radiography. The island surgery is equipped with a rudimentary X-ray machine, and limited range of point-of-care diagnostic tests. Telemedicine support is provided $24 / 7$ by British Antarctic Survey Medical Unit (BASMU) emergency 


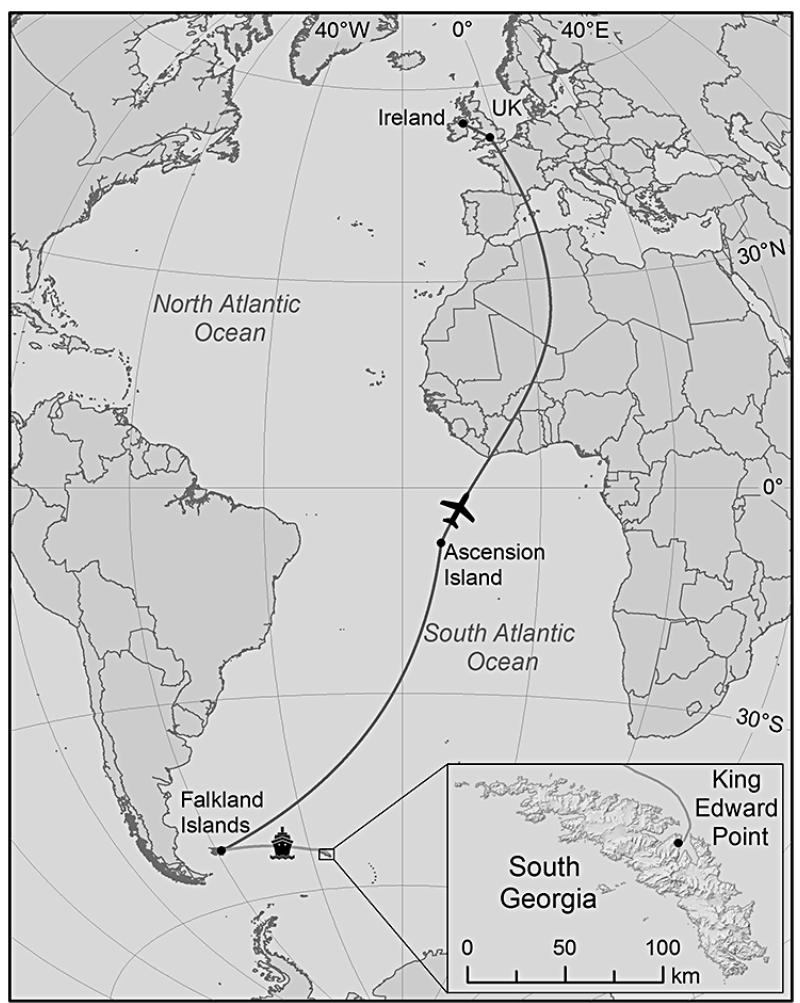

Figure 1. Location of South Georgia and route of evacuation. Image courtesy of the British Antarctic Survey Mapping and Geographic Information Centre helpdesk

physicians operating from within Derriford Hospital, a major trauma centre in the South-West region of England.

\section{CASE REPORT}

A 36-year-old boating officer presented to the island surgery after sustaining an isolated closed injury to his left knee. He had tripped over an exposed winch cable in the boatshed that morning, and landed directly onto his left patella with the joint in a flexed position. He was able to bear weight immediately, albeit with pain, and so did not attend until later that afternoon having taking simple oral analgesia. The patient had no significant past medical history and was on no regular medications.

On physical examination there was a large effusion palpable within the knee joint, and an area of localised tenderness elicited over the superior pole of the patella. The patient was able to actively straight-leg raise and had a clinically intact extensor mechanism. Full range of movement was preserved within the knee, hip and ankle joints. Given the isolated patella tenderness a plain radiograph was indicated [1]. Unfortunately there was no darkroom available on the island during the initial consultation, as a construction team were undertaking repairs to the building. The patient was therefore advised to rest, elevate the limb, and take regular analgesia until this investigation could be

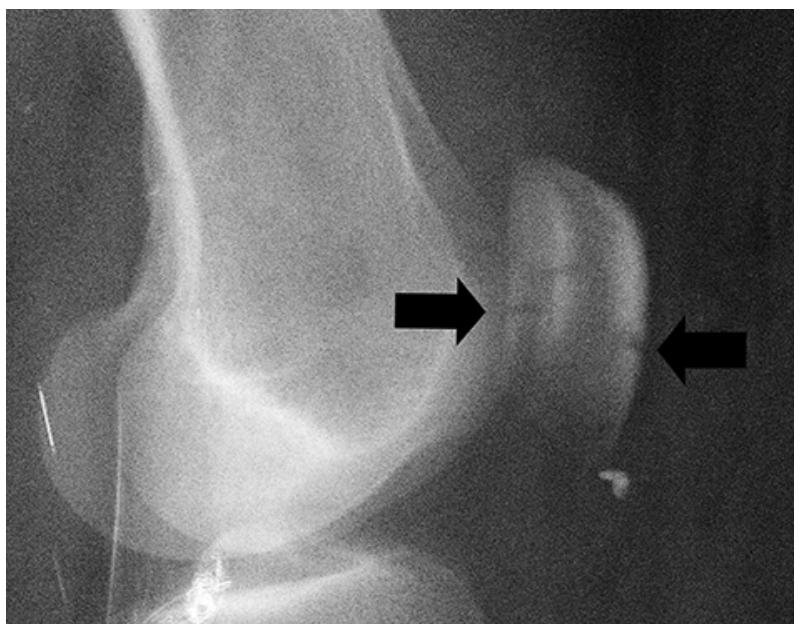

Figure 2. Lateral radiograph of the left knee, taken at the island surgery

undertaken. During the subsequent 24-h period a red light was installed in the bathroom adjacent to the island surgery. The patient returned the next day, when anteroposterior and lateral radiographs were taken. After the chemical developing process was complete, an undisplaced transverse fracture of the patella was apparent (Fig. 2). The patient was placed into a fixed extension brace, provided crutches, and advised to continue partial weight-bearing.

His clinical case was discussed with the supervising consultants at BASMU in the United Kingdom, and the radiographs forwarded electronically for an orthopaedic review. The decision was made to undertake a medical evacuation of the patient, for formal fracture clinic review and follow-up in his home country. Ten days passed before the patient could leave the island on the Royal Research Ship Ernest Shackleton, which was the next vessel scheduled to depart from South Georgia to Port Stanley on the Falkland Islands. From here, it was a further 3 day wait and $48 \mathrm{~h}$ flight transit time before the patient finally arrived home. He was seen the next day in a local orthopaedic clinic, 25 days after his original injury, where the plan to continue with non-operative treatment was made.

The patient made an uneventful recovery, continuing treatment in a fixed extension brace initially, receiving regular physiotherapy input. Six weeks after his orthopaedic clinic attendance he was declared fit to return to work. He finally arrived back to South Georgia 97 days after his accident (Fig. 3). He was able to immediately resume his normal duties as a boating officer, but still persevered with regular exercises and daily physiotherapy routines. It took an additional month before the patient regained quadriceps muscle strength to a level he was satisfied could adequately handle the South Georgian terrain. Five months after the fracture, he successfully summitted Stenhouse Peak. This 


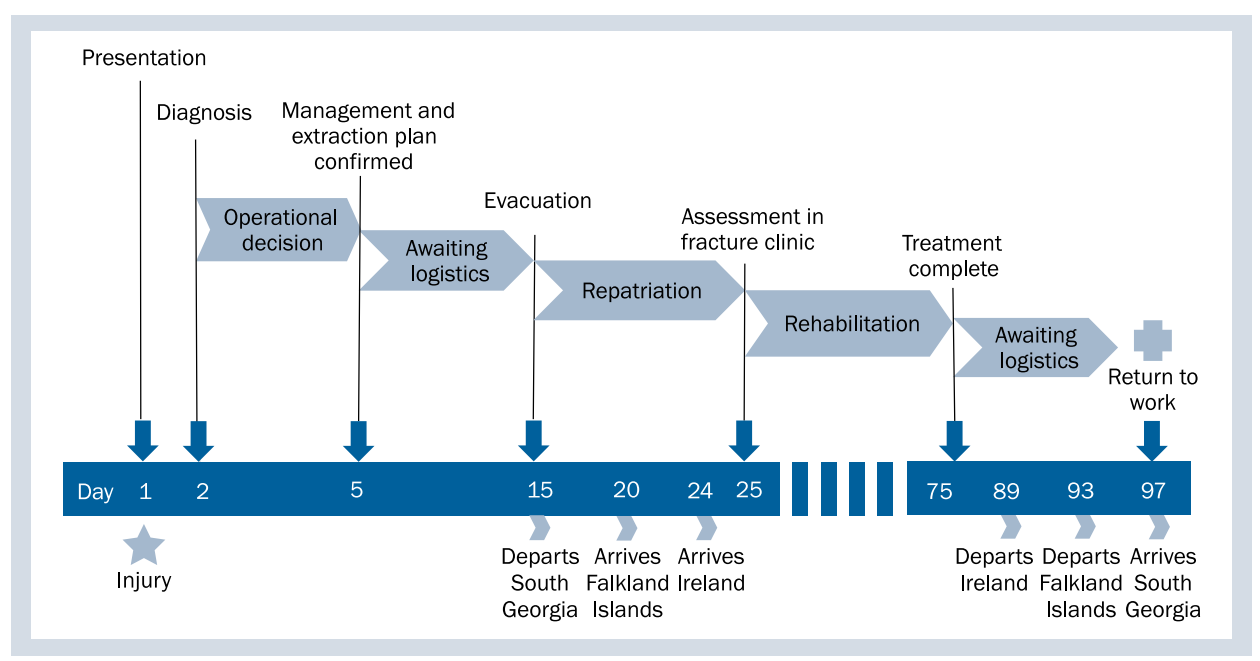

Figure 3. Timeframe of events

is one of the more challenging ascents within the field travel area, accessible only via a steep climb over loose scree.

\section{DISCUSSION}

Fractured patellae are relatively common following trauma, representing an estimated $1 \%$ of all fracture clinic attendances. In the largest recorded case series of 422 patella fractures, non-operative management was the treatment of choice in $68 \%$ of patients [2]. This study reported poor outcomes in just $1 \%$ of their non-operative cohort, after a mean follow-up period of 8.9 years. It also highlighted that $91 \%$ of non-surgically treated patients immobilised in plaster cast had returned to work at 4 months post-injury. Current evidence suggests that non-operative management is indicated for patella fractures when the extensor mechanism is intact and competent, there is less than $3 \mathrm{~mm}$ of fracture displacement, and less than $2 \mathrm{~mm}$ of articular incongruity. The use of an extension brace with partial weight-bearing as tolerated is an acceptable alternative to cylinder casting [3].

Fulfilling the above criteria, it is conceivable that our patient may have continued successfully with non-operative management whilst remaining on South Georgia. Ongoing telemedicine support could have been provided, including physiotherapy instructions and advice on repeat imaging. This would have saved considerable logistical costs to the employer. It may also be the best option available should such an injury occur at an Antarctic research station in the austral winter, when logistical support is scarce. A review of injuries sustained at Maquarie Island, an Australian research station at the same latitude to South Georgia (54 degrees South), reported just 2 lower limb fractures occurring during a 10-year study period [4]. These were both closed fractures to lateral malleoli, and were similarly managed after reduction and plaster immobilisation without necessitating patient evacuation to another facility.
However, there were additional environmental factors to be considered in this case. Firstly, the terrain on South Georgia is rugged and unforgiving. There are no tarmac roads or pavements, and the most commonly encountered surface underfoot at KEP is loose shale. To mobilise for an extended period using cruches would be challenging to say the least. Any subsequent trip or stumble could result in patella fracture displacement, or another form of physical injury, rendering further non-operative treatment an unviable option. The Maquarie Island study highlighted that $13 \%$ of all medical consultations recorded were for knee and ankle injuries, and describes the terrain on the island as being 'steep, slippery and unstable'. This statement could equally be applied to South Georgia.

Secondly, Homo sapiens are also not the only mammals to occupy the island shores during the summer months. The Antarctic fur seal (Arctocephalus gazella) is a frequent visitor to the surrounding beaches, with populations peaking between November to April during the breeding season [5]. Unfortunately this co-incided perfectly with our patient's injury and rehabilitation period. Over the austral summer male fur seals may aggressively defend any intrusion into their territory, and often claim parts of KEP research station in an attempt to secure a harem. Fur seals are agile on land, and seal bites to humans have been reported on several occasions, including one attack in 2015 that required medical evacuation to the Falkland Islands [6, 7]. In these circumstances it would be difficult for a person with limited mobility to escape from further harm.

Finally, the South Sandwich Trench poses a potential hazard to South Georgia and the South Sandwich Islands in the form of tsunami, according to the Council of Managers of National Antarctic Programmes [8]. The risk of occurrence in this region has not been quantified, but is sufficiently high to have warranted the GSGSSI to construct a tsunami shelter in 2008 on highground above a nearby whaling station. 
The entire base was rapidly evacuated with little warning in the early hours of May 2013, following an earthquake in the South Atlantic. To ascend quickly from danger, a steep scree slope above the research station needs to be climbed in accordance with the base major incident plan. This route is unlikely to be possible for an injured party given the type of terrain encountered, and so the evacuation of persons with restricted mobility appears to be the only method of mitigating this risk.

\section{CONCLUSIONS}

This case highlights some unusual environmental factors that impacted on our management of a common injury, in a seldom-reported part of the world. A planned retrieval enabled our patient to start rehabilitation and physiotherapy in a preferential setting, without causing undue delay in time taken returning to work in this remote location.

\section{ACKNOWLEDGEMENTS}

The author would like to thank Dr. Anne Hicks, Peter Marquis and the BASMU team, the staff and crew of King Edward Point Research Station and RRS Ernest Shackleton, James Millar from BAS Human Resources, and my colleague (the injured patient) who consented to this submission.

\section{REFERENCES}

1. Stiell IG, Greenberg GH, Wells GA, et al. Derivation of a decision rule for the use of radiography in acute knee injuries. Ann Emerg Med. 1995; 26(4): 405-413, doi: 10.1016/s0196-0644(95)70106-0, indexed in Pubmed: 7574120.

2. Boström A. Fracture of the patella. A study of 422 patellar fractures. Acta Orthop Scand Suppl. 1972; 143: 1-80, doi: 10.3109/ ort.1972.43.suppl-143.01, indexed in Pubmed: 4516496.

3. Melvin JS, Mehta S. Patellar fractures in adults. J Am Acad Orthop Surg. 2011; 19(4): 198-207, doi: 10.5435/00124635201104000-00004, indexed in Pubmed: 21464213.

4. McGaughey I, Sullivan P. The epidemiology of knee and ankle injuries on Macquarie Island. Injury. 2003; 34(11): 842-846, doi: 10.1016/s0020-1383(03)00032-9, indexed in Pubmed: 14580818.

5. Boyd IL. Pup production and distribution of breeding Antarctic fur seals (Arctocephalus gazella) at South Georgia. Antarctic Science. 1993; 5: 17-24, doi: 10.1017/s0954102093000045.

6. Kouliev T, Cui V. Treatment and prevention of infection following bites of the Antarctic fur seal (Arctocephalus gazella). Open Access Emerg Med. 2015; 7:17-20, doi: 10.2147/OAEM.S75442, indexed in Pubmed: 27147885.

7. Government of South Georgia \& the South Sandwich Islands. Annual Tourism and Visitor Report 2015-16. http://www.gov.gs/docsarchive (2015).

8. Council of Managers of National Antarctic Programmes (COMNAP). Understanding risk to National Antarctic Program operations and personnel in coastal Antarctica from tsunami events. http://www. ats.aq/index_e.htm (2011). 